\title{
Integrating critical cross-field outcomes in an anatomy course at a university of technology: A reflective perspective
}

\author{
J D Pillay, ${ }^{1} \mathrm{PhD} ; \mathbf{N}$ Govender, ${ }^{1} \mathrm{PhD} ; \mathbf{N}$ Lachman, ${ }^{2} \mathrm{PhD}$ \\ ${ }^{1}$ Department of Basic Medical Sciences, Faculty of Health Sciences, Durban University of Technology, Durban, South Africa \\ ${ }^{2}$ Department of Anatomy, Faculty of Health Sciences, Mayo Clinic, Rochester, MN, USA
}

Corresponding author: $N$ Govender (nalinip@dut.ac.za)

\begin{abstract}
Background. Recent trends in higher education have become particularly directed towards incorporating elements of general education in professionspecific training. Consequently, the inclusion of critical cross-field outcomes (CCFOs) - a set of generic outcomes gazetted by the South African Qualification Authority - in curricula, is directed towards stimulating a critical social conscience among students. This embraces the concept of education, more than simply certification, in embedding underlying principles that foster lifelong learning, critical thinking and social responsibility, and provides an opportune platform to examine our teaching strategies in the context of reflective practice.

Objectives. This article demonstrates an application of the theory of reflective practice in the modification of teaching strategies and the integration of the CCFOs in a human anatomy course at a university of technology.

Methods. We present the different teaching strategies that were applied, and highlight the CCFOs embodied in each approach.

Results. In so doing, we demonstrate how the integration of underpinning general education principles and discipline-specific core competencies can be easily attained through simple modifications of conventional teaching practices.

Conclusion. The teaching methods highlighted attempt to encourage and ensure that students evaluate, understand and apply their knowledge in an integrated and shared manner, as embraced by the CCFOs.
\end{abstract}

Afr J Health Professions Educ 2018;10(2):124-128. DOI:10.7196/AJHPE.2018.v10i2.960

South African (SA) higher education institutions are aligned to the Higher Education Qualifications Framework (HEQF), which is committed towards creating discipline-specific learning programmes that underpin the critical cross-field outcomes (CCFOs). ${ }^{[1]}$ These outcomes, gazetted by the SA Qualification Authority (SAQA), ${ }^{[2,3]}$ are defined as generic outcomes directed towards stimulating a critical social conscience among students. These embrace the concept of 'life-long learning, personal growth, honest business acumen, critical thinking and aesthetic appreciation, ${ }^{[4]}$ and form standard competencies that are intended to underpin all qualifications registered on the National Qualifications Framework (NQF). ${ }^{[4]}$ Split into seven critical and five developmental outcomes, the CCFOs include: the identification and solving of problems using critical and creative thinking; the use of effective teamwork within study groups, organisations and communities; organising and managing oneself and one's activities conscientiously; collecting, analysing, organising and critically evaluating information; communicating effectively using visual or language skills via oral and/or written presentations; using science and technology effectively and successfully demonstrating an understanding of the world as a set of related systems by recognising that problem-solving contexts do not exist in isolation. ${ }^{[5]}$

Recently popularised as graduate attributes, the CCFOs contribute soft skills towards empowering students to become more socially aware and responsible citizens. ${ }^{[6]}$ The aspiration to develop graduate attributes at an institution forms part of the drivers' encompassing innovation towards quality enhancement and improving the student experience, as well as creating a well-rounded graduate (K Sattar and L Cook - unpublished data,
2014). Teaching strategies therefore require reflection and consequent adaptation in an attempt to integrate discipline-specific knowledge with graduate attributes, as is promoted and required of the institution and higher education (HE).

Contemporary studies suggest that to improve and promote student learning, current curricula must explore and maximise the benefits of different teaching methods. ${ }^{[7,8]}$ A popularised approach in engaging academics towards exploring changes in teaching strategies pivots around theories on reflective practice. One of the more commonly referenced models of reflective practice is provided by Kolb, ${ }^{[9]}$ who identifies four learning stages and cycles, i.e. the concrete experience (a new experience of a situation that is encountered or a re-interprtetation of an existing experience); reflective observation (of the new experience); abstract conceptualisation (reflection giving rise to a new idea or the modification of an existing concept); and active experimentation (applying the experience globally). According to Kolb, teachers could use this framework to critically evaluate a learning provision typically available to students and to develop more appropriate teaching/learning approaches.

Academic and clinical components of formal training of most medical training programmes include anatomy as an integral component of the programme, particularly taught during the first 2 years of the academic course. Consequently, an attempt towards integrating graduate attributes in the anatomy course provides an early opportunity to exercise awareness of the CCFOs that can contribute towards such an application becoming instrinsic in the learning experience over subsequent academic years. While human dissection supplemented by formal lectures forms the basis of most 
anatomy courses, learning, both in the dissection laboratory and outside the classroom/laboratory setting, can be achieved by different teaching and learning strategies that embrace the CCFOs.

This article demonstrates an application of the theory of reflective practice in the modification of teaching strategies and the integration of the CCFOs in a human anatomy course at a university of technology. A synopsis of teaching practices that have been introduced/modified in the course to integrate the CCFOs into subject-specific content, is presented.

\section{Methods}

The Anatomy II course that is taught to allied health students within the homoeopathy and chiropractic second-year programme is primarily dissection based and includes didactic teaching (two 1-hour theory sessions per week) and practicals/dissections (three 1-hour sessions twice a week) over a 32-week year. The course is taught in the second academic year of the programme, with students having completed a similarly structured Anatomy I course during the first yearof the programme. As a follow-on from Anatomy I, the Anatomy II course includes limb and back anatomy, neuroanatomy and head and neck anatomy. As such, the anatomy of the entire human body is completed by the end of the second academic year. In highlighting some of the changes in teaching approaches within this course, the different components of the theory of reflective practice and the methodological approaches applied within each cycle of the theoretical model are summarised.

\section{Conceptual model for reflective thinking/practice}

This article highlights the application of Kolb's ${ }^{[9]}$ model on the theory of reflective practice, which identifies four learning stages/cycles that form the basis of reflective practice, i.e. the concrete experience; reflective observation; abstract conceptualisation; and active experimentation.

In the context of our study, the concrete experience relates to the introduction of innovative teaching and assessment approaches and forms the basis of this article. Much of this application relates to the fourth phase of reflective practice, i.e. active experimentation, as being the impetus for initiating the concrete experience. This is based on previous/conventional teaching and learning practices, lecturer and subject evaluations by students and consequent self-reflection in terms of 'How we do what we do' and more importantly, 'How can we effect change to improve teaching and learning?'

There are also secondary aspects that may prompt reasons for innovative teaching. In the case of this course in human anatomy, one such reason relates to the diverse learning abilities and learning styles of students in a class. A further intrinsic motivation pivots around the need to integrate the CCFOs into teaching and learning. Reflective observation centres on thinking about the experience, while abstract conceptualisation is based on the notion of learning from the experience ${ }^{[9]}$ Much of these two phases are unravelled in our article, collectively through the viewpoints of the lecturer and highlighted in the discussion. The changes in teaching strategies implemented in the course are outlined in Table 1.

The different modes of teaching strategies implemented included assignments and projects, integrated theory and practical sessions and team teaching through dissection projects.

\section{Assignments and projects}

The traditional approach included individual written assignments, e.g. to provide an account on the brachial plexus and its contributions toward the movement of the upper limb. The modified approach in this strategy was the allocation of task-specific team assignments that involved model construction related to specific body systems and their functional demonstration. Examples of such task-specific assignments included either the design of a model of the upper limb to illustrate the muscle compartments of each region, and the demonstration of its functionality as a system of levers, or the design of a three-dimensional model of the head and neck region, demonstrating the dural venous sinuses of the brain.

\section{Theory and practical sessions}

Traditionally, this approach involved independent didactic lectures, followed by dissection sessions, which were modified by integrating both lectures and practical sessions, coupled with the demonstration of models and prosected specimens that enabled immediate integration of both theoretical and practical elements.

\section{Cadaveric dissections during practical sessions}

Traditionally, formal lectures on specific anatomical areas were conducted by an academic. Students were then assigned to dissection teams that worked on an allocated cadaver. The extent of learning and personal accountability was variable and depended on the extent of involvment of each team member and their ability/interest to work together. The modified approach included team teaching through the introduction of dissection projects during the practical sessions. Teams comprised $5-6$ students, who were allocated specific dissection areas of their cadaver. Each team was required to present the specific topic/area and demonstrate their dissection area to the class in formats such as video clips, practical demonstrations, posters, PowerPoint presentations, traditional didactic teaching or a combination of one or more of these methods. Completion of this activity as a learning

Table 1. Traditional and modified approaches to teaching and learning

Mode of teaching Traditional approach

Assignment/project Written assignment
Modified approach$$
\text { Witten assign ment }
$$

Integrated theory/practical sessions

Team teaching by means of dissection projects
PowerPoint lecture and separate practical/dissection sessions Delivery (by lecturer) of formal lectures on specific anatomical areas Dissection teams work together in dissecting the allocated cadaver
Task-specific assignment, which involves model construction related to specific body systems and their functional demonstration

Combined lectures with the demonstration of models/ prosected specimens

Team teaching through dissection projects Review of learnt content by viva voce (oral assessment) and an assessment mark determined by the entire team 
outcome was achieved by engaging students in collective learning, even outside time-tabled sessions. Team members were therefore required to strategise conducive ways of working together, such as convenient meeting times, dates, venues or allocation of tasks within the project. Post-practical sessions were also included to recapitulate key concepts and assist with any challenges experienced. This strategy included oral and post-dissection assessments as a tool to determine the level of learning achieved and the quality of dissection conducted. The final assessment mark was agreed upon by all team members; teams were thus accountable for both the learning and assessment outcomes of the exercise.

\section{Results}

The modified teaching strategies implemented in relation to the seven CCFOs are shown in Table 2

Our results highlight the changes made to the anatomy curriculum in the context of integrating the CCFOs. Details of the modifications are presented in the methods section of this article.

\section{Discussion}

Allied health professionals, regardless of their occupational role, career stage or employment status, are required to be professionally competent when they exit HE institutions ${ }^{[10]}$ and enter the workforce. Therefore, HE training needs to provide professional competence that embraces the graduates' attributes. Studies conducted in the UK corroborate this need by highlighting a professional competence framework essential for enhancing the productivity of allied health professionals. ${ }^{[10]}$ These studies concluded that allied health professionals will only be able to face the forthcoming challenges if they are open to opportunities to develop reflective thinking skills that foster useful engagement and support continued professional development. ${ }^{[10]}$

Recent studies highlighted the need for educators to be more reflective about their teaching approaches towards critical thinking and clinical reasoning. ${ }^{[11,12]}$ While clinical reasoning is a key aspect of medical practice, the complexity linked to teaching and learning is most difficult owing to its invisibility to students. ${ }^{[12]}$ Some investigators explored the use of action research, ${ }^{[13]}$ in which participant engagement is promoted within a structured means of reflection regarding their teaching practices. ${ }^{[14]}$
The study explored the use of the making-thinking-visible approach and highlighted two themes, i.e. the students' understanding of the reasoning process and the increased knowledge of individual teaching approaches to demonstrating clinical reasoning. ${ }^{[12]}$ The study concluded that the makingthinking-visible approach may support educators in articulating their own expert reasoning, as well as being a potential mechanism for personal reflection. ${ }^{[12]}$ In our study, teamwork formed the basis of all the approaches used and required an effective, responsible and interactive collaboration of all team members, with the intent of enhancing personal reflection and critical thinking.

\section{Team assignments/projects}

Model construction required the interactive engagement of students to generate a functional anatomical form of the upper limb, whose functionality was determined by its movement and biomechanics. This strategy improved student creativity and problem-solving skills linked to model functionality in relation to limb anatomy. All the required CCFOs (i.e. CCFOs 1 - 7) were achieved as an otcome of this strategy. Similarly, other studies using strategies such as casts, ${ }^{[14]}$ body painting, ${ }^{[15]}$ clay modelling ${ }^{[16]}$ and construction of three-dimensional model ${ }^{[17]}$ highlight the potential value of their use as a supplement to teaching standard anatomical principles. The use of model construction in our study required extensive planning, creativity and preparation, which subsequently developed problem-solving skills to produce an aesthetically appealing, scientifically relevant and mechanically functional product. Lefroy et al.$^{[17]}$ reinforced teaching of the brachial plexus using three-dimensional pipe models. These investigators showed that the use of such models improved students' understanding of specific areas of the plexus.

The combination of knowledge-based and skills-based teaching, its application and assessment, are demonstrated in the achievement of CCFO 7. This CCFO highlighted the inter-relatedness of systems, processes and effects, and enabled multidisciplinary engagement of disciplines such as physics (through the system of levers that bring about movement), chemistry (through the chemical reactions responsible for muscle contraction and consequent movement) and biomechanics (through the application of concepts around synergism and antagonism). This was similar to the learning activity in which the dural venous sinuses of the

Table 2. Teaching strategies applied to integrate the critical cross-field outcomes

\begin{tabular}{|c|c|c|c|}
\hline \multirow[b]{2}{*}{ Critical cross-field outcome } & \multicolumn{3}{|c|}{ Modified teaching strategies } \\
\hline & Assignment & $\begin{array}{l}\text { Integrated theory/ } \\
\text { practical sessions }\end{array}$ & $\begin{array}{l}\text { Team teaching through } \\
\text { dissection projects }\end{array}$ \\
\hline $\begin{array}{l}\text { 1. Identifying and solving problems in which responses demonstrate that } \\
\text { responsible decisions using critical and creative thinking have been made }\end{array}$ & $\sqrt{ }$ & - & $\sqrt{ }$ \\
\hline $\begin{array}{l}\text { 2. Working effectively with others as a member of a team, group, organisation or } \\
\text { community }\end{array}$ & $\sqrt{ }$ & $\sqrt{ }$ & $\sqrt{ }$ \\
\hline 3. Organising and managing oneself and one's activities responsibly and effectively & $\sqrt{ }$ & $\sqrt{ }$ & $\sqrt{ }$ \\
\hline $\begin{array}{l}\text { 4. Collecting, analysing, organising and critically evaluating information, integrating } \\
\text { teaching and learning }\end{array}$ & $\sqrt{ }$ & $\sqrt{ }$ & $\sqrt{ }$ \\
\hline $\begin{array}{l}\text { 5. Communicating effectively using visual or language skills in modes of oral and/or } \\
\text { written presentation }\end{array}$ & $\sqrt{ }$ & - & $\sqrt{ }$ \\
\hline 6. Using science and technology effectively and critically & $\sqrt{ }$ & - & - \\
\hline $\begin{array}{l}\text { 7. Demonstrating an understanding of the world as a set of related systems by } \\
\text { recognising that problem-solving contexts do not exist in isolation }\end{array}$ & $\sqrt{ }$ & $\sqrt{ }$ & $\sqrt{ }$ \\
\hline
\end{tabular}


brain were demonstrated. The application of knowledge of concepts such as volume, density and flow, acquired through multidisciplinary integration of knowledge, demonstrated their inter-relatedness. The teamwork underlying these activities supports peer learning and promotes independent and critical analyses and review of all information provided by each team member, thereby enhancing the skill of being able to distinguish between relevant and irrelevant information. This outcome supported the acquisition of CCFO 4, in which skills appropriate to collecting and organising relevant information are achieved. This further promoted the conscious awareness of having a critical and analytical approach to gathering, analysing and evaluating information.

\section{Integrated theory and practical sessions}

Integrating anatomy lectures and practicals can be applied to foster selfdirected learning and reflective practice. ${ }^{[18]}$ Combining several teaching approaches, such as traditional didactic teaching, cadaveric dissections, prosections, plastination and medical imaging, complements each other and benefits the learning experience. ${ }^{[18]}$ Critical and creative thinking is therefore achieved as students develop unique ways of linking the dissected areas with theoretical background. This strategy promotes personal understanding, application and retention of key facts, as well as fostering the development of learning and recall as part of the learning experience. The strategy also encouraged the gathering of subject-relevant information and its evaluation, and consequently promoted the application of CCFOs 1, 3, 4, 5 and 7. Collecting, analysing and critically evaluating information therefore becomes an active component of the learning experience and students are expected to use the information provided, engage in and enhance further application. In some instances, formal lectures have been completely eliminated and primarily adopted as an integrated lecture and practical session within a practical setting. The assumption that students have engaged with the lecture material prior to the learning session, provides an expectation that they have some knowledge of the relevant topic. The ideal of students collecting, organising and critically analysing information is a desired outcome during teaching. Thus, the integrated nature of the practical component of this strategy lends itself to the application of various learning resources. Similarly, the integration of discipline-specific content, such as radiological techniques ${ }^{[19]}$ and co-ordinated anatomy and physiology teaching ${ }^{[20]}$ with anatomical teaching, improves the clinical student interest and the application of anatomy.

\section{Team teaching through dissection projects}

This strategy allowed the achievement of CCFOs 2, 5 and 6. The dissection experience supports group engagement/peer learning and working effectively with others as team members. Strategies employing the use of body painting were similarly reported to be successful in improving the learning experience for medical students using a team-learning approach. ${ }^{[15]}$ These studies corroborate its value as an adjunct to support the learning of human anatomy. More recently, the construction of anatomical casts was employed to improve the acquisition of anatomical knowledge. ${ }^{[14]}$ These studies have shown to improve the collaborative and problem-solving outcomes necessary to produce professional medical graduates. Thus, the teaching and learning strategy implemented in our study fosters and stimulates self-directed learning through an active (hands-on) approach. Peer learning and the use of team assignments strengthen teamwork and improve personal and peer learning through shared accountability. Teamwork is thus enhanced during the practical sessions through the introduction of combined group assessments. This increases student engagement, sharing of knowledge/learning styles and accountability. Moreover, outcomes such as problem-solving and creative thinking are achieved by means of student-directed initiatives to enhance learning, e.g. the use of diagrams, mind-maps, flowcharts and pneumonics.

Studies have shown that peer learning encourages the development of collaboration and communication skills and provides a conducive learning community that prepares students for project planning. ${ }^{[21,22]}$ This engagement empowered students to communicate their knowledge and to have it peer reviewed. ${ }^{[21]}$ Furthermore, students become accountable for recognising their own learning needs, thereby ensuring that these needs are met. Peer learning fosters a learning-how-to-learn skill, which prepares students for the co-operative interacting skills necessary to be functional employed citizens. ${ }^{[2]}$ This improves communication and self-confidence. ${ }^{[22]}$

An underlying outcome of the dissection experience, by nature of its team approach and active participation, requires the ability to communicate effectively with each other. Similarly, peer learning and group assessments/ assignments provide a need for peers to communicate effectively and develop effective language skills in written and oral forms. This approach also supports extensive student engagement as a result of their oral delivery with regard to the specific dissected regions to the class. Therefore, the achievement of CCFO 6 was improved owing to the use of various innovative and technological approaches in delivering and communicating the acquired knowledge. The extensive creativity and innovative modes of presentation, such as video recordings, interactive three-dimensional models and posters, were examples of team decisions. Thus, the team dissections and projects provided a medium for the extensive use of science and technology as an adjunct to the conventional use of the e-learning interface.

\section{Conclusion}

The value of graduate attributes in HE has gained international recognition, particularly in universities of technology where vocational needs have formed the basis of academic training. The challenge, however, is in trying to integrate qualities such as accountability and shared responsibility into programmes that have traditionally focused solely on self-betterment and professional needs. To our knowledge, this is the first study that presents information of modified teaching methods within the context of human anatomy and in relation to the CCFOs. The teaching methods highlighted in our study attempt to encourage and ensure that students evaluate, understand and apply their knowledge in an integrated and shared manner, as embraced by the CCFOs. We also demonstrated how the application of the theory of reflective practice, coupled with the drive for change by institutional and HE recommendations, can stimulate academics to consider simple ways of applying innovative teaching approaches. Studies that evaluate student perceptions regarding the teaching modifications would further support the reflective practice approach to teaching. A more objective evaluation of the benefits of change (e.g. through assessment performance) would provide useful information and direction for further application.

Acknowledgements. The authors wish to thank Mr R Maharaj for his administrative assistance during submission of the manuscript. 
Author contributions. JDP drafted and conceptualised the article. NG and NL contributed conceptually to the development of the manuscript. All authors approved the final document.

\section{Funding. None.}

\section{Conflicts of interest. None.}

1. Council on Higher Education. Work-Integrated Learning: Good Practice Guide. Higher Education Monitor 12 Pretoria: CHE, 2011

2. South African Qualifications Authority. National policy and criteria for designing and implementing assessment for NQF qualifications and part-qualifications and professional designations in South Africa. 2001. www.saqa. org.za/docs/pol/2015/National\%20Policy\%20for\%20Assessment.pdf (accessed 24 October 2016).

3. Department of Education. Annual Report 2001 - 2002. Pretoria: DoE, 2002.

. Carmichael T, Stacey A. Perceptions of SAQA's critical cross-field outcomes as key management metacompetencies. S Afr J Bus Manage 2006;37(2)

5outh African Qualifications Authority. Investigating the use of critical cross-field outcomes in the design of ABET qualifications and unit standards: Terms of reference. Pretoria: SAQA, 2006

6. Andrews J, Higson H. Graduate employability, 'soft skills' versus 'hard' business knowledge: A European study. High Educ Eur 2008;33(4):411-422. https://doi.org/10.1080/03797720802522627

7. Alexander CJ, Crescini WM, Juskewitch JE, Lachman N, Pawlina W. Assessing the integration of audience response system technology in teaching of anatomical sciences. Anat Sci Educ 2009:2(4):160-166. https://dol org/10.1002/ase. 99

8. Johnson EO, Charchanti AV, Troupis TG. Modernization of an anatomy class: From conceptualization to implementation. A case for integrated multimodal-multidisciplinary teaching. Anat Sci Educ 2012;5(6):354-366. implementation. A case for integ

9. Kolb DA. Experiential Learning: Experience as the Source of Learning and Development. 2nd ed. New Jersey Kolb DA. Experiential Learnin:
USA: Pearson Education, 2014.
10. Cross V, Liles C, Conduit J, Price P. Linking reflective practice to evidence of competence: A workshop for allied health professionals. Reflect Pract 2004;5(1):3-31. https://doi.org/10.1080/146239403200016993

11. Postgraduate studies in South Africa - a statistical profile. 2009. http://www.che.ac.za/documents/d000196 (accessed 23 November 2016)

2. Delany C, Golding C. Teaching clinical reasoning by making thinking visible: An action research project with allied health clinical educators. BMC Med Educ 2014;14(1):20. https://doi.org/10.1186/1472-6920-14-20

13. McNiff J, Whitehead J. All You Need To Know About Action Research. London: Sage, 2006.

14. Hermiz DJ, O'Sullivan DJ, Lujan HL, DiCarlo SE. Constructivist learning of anatomy: Gaining knowledge by creating anatomical casts. Anat Sci Educ 2011;4:98-104. https://doi.org/10.1002/ase.206

15. McMenamin PG. Body painting as a tool in clinical anatomy teaching. Anat Sci Educ 2008;1(4):139-144. https:// doi.org/10.1002/ase. 32

16. Chang-Seok O, Ji-Young K, Yeon HC. Learning of cross-sectional anatomy using clay models. Anat Sci Educ 2009;2(4):156-159. https://doi.org/10.1002/ase.92

17. Lefroy $\mathrm{H}$, Burdon-Bailey V, Bhangu A, Abrahams P. A novel technique for teaching the brachial plexus. Clin Teach 2011;8(3):196-199. https://doi.org/10.1111/j.1743-498x.2011.00448.x

18. Estai M, Bunt S. Best teaching practices in anatomy education: A critical review. Ann Anat 2016;208:151-157. https:// doi.org/10.1016/j.aanat.2016.02.010

19. Heptonstall NB, Ali T, Mankad K. Medical education in the UK - the evidence, current trends, and future scope Acad Radiol 2016;23(4):521-526. https://doi.org/10.1016/j.acra.2015.12.010

20. Kageyama I, Yoshimura K, Satoh Y, Nanayakkara CD, Pallegama RW, Iwasaki S. Proposal for research and education: Joint lectures and practicals on central nervous system anatomy and physiology. J Physiol Sc 2016;66(4):283-292. https://doi.org/10.1007/s12576-015-0428-x

21. Boud D, Cohen R, Sampson J. Peer learning and assessment. Assess Eval High Educ 1999;24(4):413-426. https:/ doi.org/10.1080/0260293990240405

22. Stone $\mathrm{R}$, Cooper $\mathrm{S}$, Cant $\mathrm{R}$. The value of peer learning in undergraduate nursing education: $\mathrm{A}$ systematic review ISRN Nurs 2013;2013:1-11. https://doi.org/10.1155/2013/930901

Accepted 21 November 2017 